\title{
Soldados orientalistas: teosofía y masonería en el Magreb durante la II República Española
}

\section{Orientalist soldiers: Theosophy and Freemasonry in North Africa during Second Spanish Republic}

\author{
Valeria Aguiar Bobet \\ Becaria-contratada FPU-2013 por el MECD. Grupo de Investigación Historia Social Comparada de la \\ Universidad Jaume I de Castellón, España. Correo electrónico: vaguiar@uji.es \\ DOI: http://dx.doi.org/10.15517/rehmlac.v8i2.26648
}

Fecha de recibido: 21 de agosto de 2016 - Fecha de aceptación: 17 de octubre de 2016

\section{Palabras clave}

Protectorado español de Marruecos; II República Española; esoterismo; militarismo

\section{Keywords}

Spanish Protectorate in Marroco; Second Spanish Republic; esotericism; militarism

\begin{abstract}
Resumen
La vinculación entre masonería y teosofía ha sido objeto de distintos análisis por parte de la historiografía, sobre todo porque muchos masones españoles pertenecieron a su vez a distintos movimientos y asociaciones teosóficas que se expandieron y constituyeron por todo el territorio nacional desde finales del siglo XIX. Sin embargo, en el Protectorado español de Marruecos, la mayor parte de los integrantes y simpatizantes de la Sociedad Teosófica no solo fueron masones y teósofos, sino que fueron militares de diferente graduación. El propósito de este trabajo es, precisamente, aproximarnos a la relación entre este trinomio particular, la masonería, la teosofía y el estamento militar, a partir del análisis ideológico de las prácticas y discursos de aquellos miembros de esta asociación. Sin olvidar, por un lado, cómo se estructuró y definió esta interrelación ideológica en el contexto republicano y colonial de marcado carácter militar, y, por otra, cómo influyó en los procesos sociopolíticos que vivía España y su Protectorado en los años previos a la Guerra Civil.
\end{abstract}

\begin{abstract}
The link between Freemasonry and Theosophy has been the subject of a variety of analyses throughout masonic historiography. This is largely because many Spanish masons belonged to different theosophical movements and associations, which were expanded and established throughout the country beginning in the late nineteenth century. However, in the Spanish protectorate in Morocco, most of the members and supporters of the Theosophical Society were not only masons and theosophists, but also military personnel with different ranks. The purpose of this work is to approach the relationship between Freemasonry, Theosophy and militarism, based on an ideological analysis of the practices and discourses of the members of this association without forgetting, on the one hand, how this ideological interplay was structured and defined in the republican and colonial context for military purposes, and on the other hand, how it influenced the socio-political processes that Spain experienced in the years before the Civil War.
\end{abstract}


La vinculación entre masonería y teosofía ha sido objeto de distintos análisis por parte de la historiografía, sobre todo porque muchos masones españoles pertenecieron a su vez a distintos movimientos y asociaciones teosóficas que se expandieron y constituyeron por todo el territorio nacional desde finales del siglo XIX. Es más, muchos de los integrantes de la Sociedad Teosófica, en sus diferentes ramas, fueron conocidos masones. El caso más notorio fue el de Mario Roso de Luna o, también, el de Manuel Treviño Villa. Asimismo, en el Protectorado español de Marruecos, la mayor parte de los miembros de la Sociedad Teosófica, algunos simpatizantes o integrantes de diferentes corrientes esotéricas y practicantes del espiritismo, el esperantismo y el ocultismo, pertenecieron a la orden masónica. Sin embargo, esta relación no ha sido lo suficientemente estudiada precisamente por la juventud de los estudios sobre el esoterismo que, afortunadamente, se han incentivado en la última década. Si a esto añadimos la conexión de estas asociaciones con la tipología de sus integrantes, el resultado historiográfico es mucho menor.

En el caso español y en concreto el norteafricano, un grupo bien definido destaca como integrante y potenciador de estas corrientes teosóficas y esotéricas, los militares, cuya relación con la masonería, al contrario que con el esoterismo, sí ha sido puesta en relieve. La presencia constante y omnipresente del ejército es un hecho particular español por su propio bagaje histórico $\mathrm{y}$ por el significado sociocultural que presenta para el primer tercio del siglo XX, produciendo que las relaciones entre el poder civil y el poder militar, tal y como afirma Carlos Seco Serrano, "constituyan la clave esencial para la comprensión de la Historia Contemporánea española"1. Además, de sobra conocida es la presencia militar en el Norte de África por razones obvias: la mayor parte de la población española que residía en el Protectorado antes de la II República pertenecía a la milicia, debido por un lado, a la larga empresa de pacificación del territorio colonial que duraría desde 1921 hasta 1927, como a razones estratégicas y administrativas de la colonia. Numerosas cabilas seguían en rebeldía en los albores de 1930, por lo que el control del territorio, en la práctica, no estaba del todo estabilizado. Se trataba de una zona ocupada, colonial en un espacio descentralizado política y socioeconómicamente por parte del Majzén, la administración marroquí, y, a su vez, una zona fronteriza frente a España y sus plazas de soberanía, Ceuta y Melilla.

El propósito de este trabajo es, precisamente, aproximarnos a la relación de este trinomio particular - la masonería, la teosofía y el militarismo - a partir del análisis ideológico de las prácticas y discursos de aquellos miembros de esta asociación. Sin olvidar, por un lado, cómo se estructuró y definió esta interrelación ideológica en el contexto republicano y colonial con grandes contradicciones cívico-militares y, por otra, cómo influyó en los procesos sociopolíticos que vivían España y su Protectorado en los años previos a la Guerra Civil.

\footnotetext{
${ }^{1}$ Carlos Seco Serrano, Militarismo y civilismo en la España contemporània (Madrid: Instituto de Estudios Económicos, 1984), 13-14.
} 


\section{Límites y divergencias a propósito de los conceptos}

Antes de adentrarnos en el tema que nos ocupa, es necesario mencionar las diferencias conceptuales y terminológicas de algunos de los nombres utilizados en este trabajo o, al menos, el uso que se dará de ellos. La razón de ello es la propia controversia histórica e historicista de los términos teosofia, teósofos, esoterismo o "lo esotérico", esoterismo occidental, espiritismo, etcétera. De todos modos, no es nuestro objeto desarrollar la discusión historiográfica que se encontrará en otros trabajos dedicados ex profeso a ello ${ }^{2}$; al contrario, trataremos aquí de englobar estos movimientos de forma genérica en su espacio geográfico y geopolítico, de tal forma que en sus menciones subsiguientes a lo largo del texto pueda el lector entender su uso específico.

De este modo, si comenzamos nuestras matizaciones conceptuales de lo general a lo particular, nos encontramos que desde finales del siglo XIX y durante el primer tercio del siglo $\mathrm{XX}$, unas determinadas élites intelectuales y artísticas occidentales apostaron por una alternativa social e ideológica ante la crisis social, religiosa y cultural en la que estaba sumida Europa. El término que se emplea para agrupar estas mentalidades alternativas es el nuevo humanismo internacional que, en líneas generales, pretendía ofrecer una moral hecha de valores universales como la sinceridad, la solidaridad, la cooperación, el pacifismo o el diálogo en detrimento de sus opuestos imperantes: el positivismo, el materialismo, la moral burguesa victoriana, el dogmatismo racionalista, el catolicismo familiar o tradicional, etcétera. Eran movimientos, según establece J. Pomes, "que tenían en común la oposición al modelo político conservador y católico de entender el mundo e interpretarlo, pero también la creencia en algunos ideales humanitarios, sobre todo la fe en el progreso"3 que, además, compartieron durante algunas décadas espacios de relación y ámbitos culturales, científicos e ideológicos. El modernismo, orientalismo, esperantismo, movimientos de renovación pedagógica, pacifismo, librepensamiento o feminismo, medicinas naturistas, vegetarianismo, teosofía, masonería, diferentes movimientos esotéricos o espiritistas, etcétera., conforman este nuevo humanismo cuyas conexiones fueron tan numerosas, intensas y profundas que muchas veces es difícil trazar las fronteras entre unos y otros.

No obstante, de entre todos estos movimientos del nuevo humanismo, nos interesa destacar aquí su versión espiritual, es decir, el teosofía, el espiritismo, ocultismo y en general, todos aquellos movimientos que hoy se engloban en el denominado esoterismo occidental. Para ello, debemos aclarar primero las diferencias conceptuales que suponen estas corrientes, cuyas delimitaciones, también están muy difuminadas, tanto para sus contemporáneos y protagonistas, como para los historiadores, quienes debemos realizar un gran esfuerzo para interpretarlos desde su justa inteligibilidad. ¿Cómo se define el esoterismo en el mundo académico? Así lo estipula la Asociation for the Study of Esotericism (ASE) en su web:

\footnotetext{
${ }^{2}$ Véanse los trabajos de Antoine Faivre, Jacob Needelman, Wouter Hanegraaff, etcétera.

3 Jordi Pomes Vives, "Diálogo de Oriente y Occidente en la España de finales del siglo XIX. El primer teosofismo español (1888-1906): un movimiento religioso heterodoxo bien integrado en los movimientos sociales de su época", Revista HMIC IV (2006): 55-75.
} 
Esoterismo, en el ámbito académico, hace referencia a los estudios de movimientos religiosos o filosóficos alternativos o marginalizados cuyas partidarios, en general, distinguen sus propias creencias, prácticas y experiencias de las tradiciones religiosas públicas institucionalizadas. Entre las áreas de investigación que abarca el estudio del esoterismo se encuentran la alquimia, la astrología, el gnosticismo, el hermetismo, Kabbalah, magia, misticismo, neoplatonismo, movimientos religiosos actuales, movimientos ocultistas de los siglos XIX, XX y XXI, Rosacruces, sociedades secretas y el cristianismo teosófico 4 .

El concepto esoterismo como constructo académico, por tanto, engloba todos aquellos movimientos espiritistas, teósofos o las denominadas sociedades secretas tildadas de estas características. La Sociedad Teosófica, denominada como teosofismo, por René Guénon para establecer su diferencia con respecto de la teosofía, forma parte integrante de este, que debe diferenciarse a su vez del espiritismo, el ocultismo, esperantismo, la masonería, etcétera. En ningún momento incluimos la masonería como parte de este esoterismo, pero sí podemos afirmar que está inserta dentro del nuevo humanismo que engloba a esta totalidad de movimientos y que, incluso, tiene elementos concordantes con la teosofía, como ya han apreciado diversos autores y como nosotros especificaremos más adelante.

Mención especial merecen los términos comasonería y Le Droit Humain o El Derecho Humano, ambos ramas de la masonería irregular, en este caso, mixta, que se configurarían a finales del siglo XIX desde el feminismo incipiente que se fraguaba en la época. El primero pertenecía a Inglaterra y el segundo a Francia, pero ambos tenían una gran afinidad con la teosofía, como el resto de las corrientes, del mismo modo que la Sociedad Teosófica se nutría y participaba de ellos. René Guénon comenta estas vicisitudes desde 1921, donde en su obra crítica de la Sociedad Teosófica ${ }^{5}$ refería los propios cambios ideológicos de esta y todas sus contradicciones desde su primera fundadora Helena Blavatsky hasta la líder, contemporánea a este escrito, Annie Besant, quien pertenecería además, a esta orden mixta.

Muchos de estos movimientos, sin embargo, no están institucionalizados o formalizados en España en estos momentos, o bien su difusión fue más lenta aunque significativa. Tan solo encontramos la Sociedad Teosófica con este cariz, si bien otros individuos podían estar afiliados a

\footnotetext{
${ }^{4}$ Traducción del original: "Esotericism, as an academic field, refers to the study of alternative or marginalized religious movements or philosophies whose proponents in general distinguish their own beliefs, practices, and experiences from public, institutionalized religious traditions. Among areas of investigation included in the field of esotericism are alchemy, astrology, Gnosticism, Hermeticism, Kabbalah, magic, mysticism, Neoplatonism, new religious movements connected with these currents, nineteenth, twentieth, and twentyfirst century occult movements, Rosicrucianism, secret societies, and Christian theosophy". Association for the Study of Esotericism (2016 [citada el 28 de octubre de 2016]): disponible en http://www.aseweb.org/?page $\mathrm{id}=13$

${ }^{5}$ René Guénon, Teosofismo, historia de una pseudo-religión (1921), trad. C. J. Vega (Montevideo: Edición digital de la Dirección de Educación del Ministerio de Educación y Cultura, s.a. [citado el 16 de febrero de 2016]): disponible en http://www.edu.mec.gub.uy/biblioteca digital/libros/G/Guenon, $\% 20$ Rene $\% 20$ \%20religion.pdf
} 
Le Droit Humain en Francia o asistir a sesiones de espiritismo sin estar regladas. Del mismo modo, tampoco sus integrantes o simpatizantes españoles pulularon de un modo dogmático o tajante en cada uno de ellos, es más, sus vinculaciones a veces son relativas y dependen del propio sujeto y sus intereses. Así tenemos un mismo individuo masón que a su vez es teósofo y espiritista, sintiendo con mayor fuerza una u otra, o simplemente tenemos otros personajes que, siendo exclusivamente masones, están interesados en las doctrinas teosóficas, en la masonería mixta, las sesiones espiritistas o médiums. Probablemente, las limitaciones de una $\mathrm{u}$ otra rama eran imperceptibles para muchos de ellos, siendo únicamente su esencia, digamos, alternativa a la moral tradicional imperante, la atracción que les convidaba a acercarse a sus preceptos.

Sin poder entrar en más detalles, especificamos pues, que haremos un uso general del concepto esoterismo para explicar todos aquellos movimientos espirituales y espiritistas que interesaron a los masones norteafricanos en el periodo republicano: teosofia, esperantismo, ocultismo, obscurantismo, mediumnidad, masonería mixta, etcétera. El resto de matices se irán indicando en el texto.

\section{La Sociedad Teosófica en el Protectorado marroquí}

En líneas generales, la Sociedad Teosófica en España tuvo una lenta pero progresiva implantación. A principios de 1917, constaban en sus filas 209 miembros integrados en cinco Ramas (Madrid, Barcelona (2), Tarrasa y Sevilla), varios grupos (Ceuta, Melilla, Orán, Tenerife, Palma de Mallorca, Valencia, Alicante, Murcia y Tarragona), además de individuos independientes por diversas ciudades ${ }^{6}$. Cuatro años más tarde su crecimiento iría en aumento pues se constituirían cinco ramas más, Valencia (1918), Alicante (1919), Zanoni (1919), Cádiz (1919) y Dharma (1920); extensión que permitirá, además, en octubre de 1921, solicitar oficialmente la Carta Constitutiva de la Sección Española de la Sociedad Teosófica. Con ello, también, se añadían algunos cambios: la creación de la "Rama Hesperia, rama Hispano-Americana y Marroquí" en 1921 y potenciada a partir de 1925 y La Rama Bilbao, fundada el 29 de septiembre de $1927^{7}$. En los albores de la II República, de este modo, existían en España alrededor de una veintena de ramas ${ }^{8}$.

La situación de la Sociedad en el Protectorado resultó similar, con un número escaso de miembros pero en continua ascendencia durante el primer tercio del siglo XX, a lo que se añadía otro grupo numeroso de simpatizantes, lectores o interesados en materias esotéricas o ciertas vinculaciones con la masonería mixta. Según Vicente Penalva Mora en

\footnotetext{
${ }^{6}$ Véase Vicente Penalva Mora "El orientalismo en la cultura española en el primer tercio del siglo XX. La Sociedad Teosófica Española (1888-1940)" (Tesis de Doctorado en Historia, Universidad Autónoma de Barcelona, 2013), 76.

${ }^{7}$ Los datos han sido tomados de la tesis de Penalva Mora, "El orientalismo en la cultura española", 99.

${ }^{8}$ Penalva Mora, "El orientalismo en la cultura española", 70-71.
} 
su tesis sobre "La Sociedad Teosófica Española (1888-1940)", , los integrantes en el Norte de África durante el periodo republicano fueron: seis en Tetuán, diez en Ceuta y treinta y seis en Melilla, aunque debe tenerse en cuenta que muchos de los expedientes personales de los socios o sus registros desaparecieron por diversas causas a comienzos de la Guerra Civil en 1936. Además, muchos de estos componentes figuraban en Ramas de otras provincias como Palma de Mallorca o Bilbao, precisamente por la movilidad y los traslados a causa de sus profesiones, sobre todo, de los profesionales militares.

Por otro lado, su implantación en el Magreb desde el segundo semestre de 1912, se debe a los capitanes de Infantería César Bordoy García y Julio Garrido Ramos, el comandante médico Fernando Muñoz y José Guerru, quienes constituyeron varios grupos de estudios teosóficos durante un viaje realizado por las ciudades más importantes del territorio. Así, en Tánger se reunieron con varios miembros de la Orden de la Estrella de Oriente; en Tetuán, acompañados de David Cheriqui, visitaron al Dr. Guita, médico de la colonia judía, y otros personajes relevantes de la comunidad musulmana como Sidi Ben Abeir, ante quienes leyeron los objetivos y principios de la Sociedad Teosófica, y la mayor parte del artículo de Annie Besant "El Islam a la luz de la Teosofía".

La razón de este objetivo e interés de la implantación de la Sociedad en el Protectorado, viene determinado por varios factores. En primer lugar, por la consideración de que la teosofía no solo era propia de las tradiciones filosóficas y religiosas de Oriente y Occidente, sino que igualmente se encuentra implícita en la cultura musulmana. De hecho, existieron algunos teósofos conversos al Islam como René Guénon. Mención aparte requiere la dedicación de algunos artículos publicados en la revista teosófica Sophia ${ }^{10}$. En este sentido, Julio Garrido, con afán propagandístico y divulgativo de los preceptos teosóficos, escribió a los presidentes de las Ramas de El Cairo, Túnez, Susa, Bizerta, Argel y Orán, pidiéndoles noticias de los trabajos efectuados por ellos en el mundo del Islam, con la finalidad de "unificar esfuerzos, encauzar la propaganda y lograr quizá más tarde una federación de todos los grupos del Norte de África, que pudiera servir de germen para una futura Sección internacional norteafricana de la Sociedad Teosófica"11. Esta sección, además, encerraba otra particularidad:

La difusión de la Teosofía en Marruecos es una labor lenta pero de resultados incalculables, y quizás en su día el mismo Gobierno español, conociendo el valor de las enseñanzas teosóficas para suavizar las diferencias religiosas y etnológicas y hacer obra positivamente civilizadora, reconozca y apoye como de utilidad pública la obra de la $\mathrm{S}$. T.

\footnotetext{
${ }^{9}$ Penalva Mora, "El orientalismo en la cultura española", 69-70.

${ }^{10}$ Viriato Díaz-Pérez publicó dos artículos "Sobre el Misticismo Musulmán" en Sophia (enero de 1901), 27-34 y Sophia, (febrero de 1901), 52-54; y "Los manuscritos árabes aljamiados sobre el ocultismo que existen en la Biblioteca Nacional", Sophia, (agosto de 1903), 290-294. Mario Roso de Luna publicó el artículo "Mirando hacia el Sáhara", Sophia (julio de 1907). Posteriormente, Julio Garrido tradujo de The Theosophist un interesante artículo sobre "Teosofia y Sufismo", publicado en Sophia, (octubre y noviembre de 1912). Véase Penalva Mora, "El orientalismo en la cultura española", 70-71.

${ }^{11}$ Penalva Mora, "El orientalismo en la cultura española", 70-71.
} 
En su área de influencia, al igual que ha hecho el Gobierno inglés en el vasto imperio de la India $^{12}$.

La actividad divulgativa y expansiva de la Sociedad en el Norte de África se definía, por tanto, como parte de la labor civilizadora del territorio y sus gentes, en relación con la misión de España como país protector, tal y como ocurrirá con la constitución y expansión de la masonería ${ }^{13}$. Así, se desarrollarán en los años siguientes las Ramas en Melilla (1926), Ceuta (1932) y Tetuán (1931) a pesar de que la federación soñada por Julio Garrido no llegase nunca a constituirse. No obstante, los creyentes que pertenecían a diferentes tradiciones culturales, en estos grupos teosóficos, eran capaces de relacionarse en recíproca actitud de tolerancia y respecto, sin la desigualdad imperante por motivos religiosos o culturales comunes entre musulmanes, cristianos o judíos, del mismo modo que ocurriría en las logias masónicas. Aunque, también es cierto, pocos fueron los judíos y musulmanes que se adhirieron, formalmente a la Sociedad, o al menos no se han encontrado pruebas aún de esta adhesión formal como veremos más adelante.

A pesar de ello, la teosofía, en toda su extensión y al igual que otras corrientes esotéricas, implicó a una parte de la intelectualidad española y estuvo estrechamente relacionada con diversos movimientos sociales y políticos de principios de siglo. En ningún caso se trató "de un fenómeno marginal, o como el occult underground occidental, ya que creyentes y practicantes no se encontraron nunca en los márgenes de la sociedad"14. Al contrario, fueron personajes de la alta sociedad y de la clase media culta sus primeros adeptos, aumentando su base popular una vez que se expandía y generalizaba. De hecho, fueron intelectuales, científicos y otros profesionales los que con mayor ímpetu manifestaron su atracción hacia los fenómenos del ocultismo o del espiritismo. Podría señalarse, incluso, que se trataba de una moda el asistir a este tipo de sesiones o conferencias sobre el esperanto, etcétera, que solo en pocas ocasiones -médiums, ocultismos-, entraban en contradicción con otras creencias o valores tradicionales, al menos a priori.

La tipología de la afiliación a nivel nacional así lo confirma: constan 725 registros (un $55 \%$ ) de los que, por una parte destaca un grupo no muy numeroso de personas cualificadas, con estudios universitarios o profesiones liberales, que habitualmente

\footnotetext{
${ }^{12}$ Sophia, (octubre de 1912): 617. En diversos estudios se ha especificado el papel de la Sociedad Teosófica con el colonialismo, por ejemplo al respecto de Helena Blavatsky o Annie Besant con la India. La primera por ser un vehículo del colonialismo británico, hecho criticado por René Guénon desde 1921 en su obra ya citada, como por la segunda, esta vez a favor de su descolonización. No obstante, esta relación entre la Sociedad Teosófica y el colonialismo y orientalismo, se dejará para otra ocasión.

13 Véase Manuel de Paz Sánchez, "España, Cuba y Marruecos: masonería, identidades y construcción nacional", Anuario de Estudio Atlánticos 55 (2009), 273-310; y Valeria Aguiar Bobet, "La cultura de la tolerancia en el Marruecos de la II República: el VIII Centenario de Maimónides", eds. José Miguel Delgado Idarreta e Yván Pozuelo Andrés, La masonería hispano-lusa y americana, De los Absolutismos a las Democracias (1815-2015) (Zaragoza: CEHME, de próxima publicación 2017).

${ }^{14}$ Véase Francisco Tortosa, Héctor González-Ordi y Juan José Migguel-Tobal, "La hipnosis. Una controversia interminable", Anales de Psicología 15, no. 1, (1999): 15.
} 
ocupaban los cargos directivos más representativos. En el Consejo Nacional de 1922 y años sucesivos se integran médicos, abogados, militares, ingenieros, escritores o funcionarios. Y por otro lado, en las ciudades con una población eminentemente obrera, como las de la periferia de Barcelona, Gijón y Bilbao, se divulga entre una población que durante el primer tercio del siglo XX está accediendo en masa a esta cultura, apareciendo así entre sus filas, amas de casa, comerciantes, pequeños industriales, obreros y personas menos cualificadas. Y es que la comprensión de los presupuestos teóricos de la filosofía, ciencia y religión no era cuestión de unos pocos; naturalmente todo individuo con preocupaciones espirituales podía acceder. Facilitar este proceso era misión de la Sociedad, tal y como planteaba su impulsora H. Blavatsky ${ }^{15}$.

Además, como ya han demostrado algunos especialistas, en el ámbito de la sociabilidad republicana confluyeron espiritistas, teósofos, masones, librepensadores, y se interrelacionaron con las diversas agrupaciones políticas, incluso compartiendo afiliación y el mismo espacio físico en el Casino, en el Ateneo o en los cafés en diversas ocasiones.

Aunque no existió un programa político concreto de la Sociedad Teosófica en España, sí se sumaron a su manera a la corriente regeneracionista que se extendió por España en la primera década del siglo desde un republicanismo heterodoxo. Y precisamente por estas razones, muchos masones, espiritistas, librepensadores, naturistas, etcétera, se afiliaban a la Sociedad, dado que sus preceptos y objetivos se articulaban perfectamente para dar cabida a una pluralidad de sensibilidades y perspectivas. Un gran número de personas podían encontrarse cómodas en su interior, pues el único requisito para la afiliación era suscribir el primero de los principios, es decir, la práctica de la fraternidad. Esta era una aspiración muy común en un conjunto de colectivos que veían en ella la clave para la regeneración humana y social que sentían tan necesaria. En el contexto del Protectorado se añadía, además, la obra civilizadora y colonial del territorio marroquí, aunque será la masonería la institución que mayor labore a este respecto.

\section{El pensamiento esotérico y teosófico en las logias norteafricanas}

La doctrina teosófica, a priori, no entraba en colisión con la masonería. Es más, eran totalmente complementarias, sobre todo desde una interpretación esotérica de la tradición masónica. Fueron bastantes los teósofos que pertenecieron a los diversos talleres de los Hijos de la Viuda establecidos en España, aunque la obediencia a la que se adscribieron por excelencia fue la masonería mixta, sobre todo la comasonería, y la Orden Internacional El Derecho Humano. Teósofos, espiritistas, ocultistas, esperantistas o bien varias de estas situaciones combinadas, se reunían y mimetizaban en los mismos círculos masónicos. En

\footnotetext{
${ }^{15}$ Helena Blavatsky, La Clave de la Teosofía, trad. Consuelo Burón Guillén (Barcelona: Editorial Teosófica, 1889).
} 
las logias norteafricanas, además, algunas de estas prácticas y grupos eran un aspecto digno de elogio y un requisito a favor para el ingreso en la Orden, tal y como se refleja en alguno de los informes sobre "profanos":

Ilustración: lo creo estudioso, culto. Muy enterado de espiritismo y teosofía por lo que siente verdadera afición. Los libros teosóficos le atraen, le subyugan. La teoría teosófica es su ideal, mirando más que como teósofo como masón, con los que está casi completo de acuerdo.

Ideas políticas: es liberal, está afiliado a la Orden Masónica, mixta internacional "Le Droit Humain" en la que tiene el grado de aprendiz masón. Sus toques y palabras son como los nuestros. Su juramento exacto. Sus ideas los mismos, con ligerísimas variantes.

Ideas religiosas: practica teoría teosófica. No admite la inefabilidad del Papa, ni la confesión ${ }^{16}$.

Se trataba, por tanto, de una circunstancia positiva que implicaba, para los miembros de las logias, no solo una aptitud intelectual y espiritual positiva, sino que presentaba elementos que concordaban con la Orden: la jerarquía, la gradación, el ceremonial, la fraternidad universal como ideal esencial, el juramento del silencio, la educación como medio para llevarlo a cabo, etcétera. De hecho, a diferencia de la valoración que se le otorgaba a la pertenencia a religiones como la católica o a cualquier tendencia religiosa - ya fuese musulmán, católica o judía-, ser teósofo, espiritista o simpatizar con cualquier doctrina esotérica implicaba un dato a favor, útil para la Institución. Esta vinculación especial es ratificada por Cristóbal de Lora, venerable maestro de Oriente $\mathrm{n}^{\mathrm{o}} 451$ de Tetuán y Secretario de la Gran Logia de Marruecos, ex-militar y miembro de la Sociedad en una conferencia realizada en una tenida de la logia Hércules $\mathrm{n}^{\circ}$ 446 de Ceuta:

Es tan especial el concepto que me he formado [de masonería], que considero hacen falta muchos conocimientos y mucho entusiasmo por el estudio de las ciencias masónico-teosóficas, puesto que la Masonería y la Teosofía están tan íntimamente ligadas que debemos considerarlas como ramas de un mismo tronco, y no es posible desentrañar ningún sentido oculto masónico sin estudiar previamente el esoterismo teosófico ${ }^{17}$.

No podemos confirmar, exactamente, el número de integrantes teosóficos en las logias, dado que no siempre aparece reflejado este hecho en los expedientes masónicos o

\footnotetext{
${ }^{16}$ Informe de Cristóbal de Lora sobre Fernando Moraleda Hidalgo, miembro de Atlántida $n^{\circ} 448$ y posteriormente de Oriente $n^{\circ} 451$, CDMH, Sección Masonería A, Leg. 35 Exp. 11.

${ }^{17}$ Carta de Cristóbal de Lora a Hércules de Ceuta de 17 de julio de 1931. CDMH, SE Masonería A, Leg. 168 Exp. 1-2.
} 
bien no se encuentran sus correspondientes expedientes como ya se dijo. No obstante, conocemos la afiliación de algunos de los masones integrantes de estos talleres como miembros de la Orden Estrella de Oriente, de diferentes ramas de la Sociedad Teosófica como la Maitreya, la bilbaína, o bien la Liga de los Derechos del Hombre, la Asociación Esperantista Española o simplemente, como sujetos interesados y estudiosos de los preceptos defendidos por estas diversas corrientes esotéricas.

Los numerosos nombres simbólicos relacionados con el tema, por ejemplo, nos ayudan también a conocer el número y su importancia en la masonería magrebí: Budha, Eseo, Roso de Luna, Platón, Hibamari, Abioni Krishnamurti, Arquímides, el creador del esperanto L. L. Zamenhof, etcétera. En concreto, como miembros oficiales de la Sociedad Teosófica, sin contabilizar aquellos masones afiliados a las Ramas de Ceuta y Melilla, se encuentran: Antonio Montoya Hurtado de Mendoza (y tal vez su hermano Manuel miembro de Alfa $n^{\circ} 80$ de la Gran Logia Española), el antes mencionado Cristóbal de Lora Castañeda; Horacio Bruzón Carló, miembro y fundador de Luz no 449 y de Alfa $n^{\circ} 80$, ambas de Tetuán, auspiciadas, la primera por el Gran Oriente Español y la Gran Logia Española respectivamente; Antonio Marañés Portales perteneciente a Atlántida $n^{\circ} 448$ de Tetuán; y Juan Ibáñez Lugea, también de este último taller; tres de los cuales, además, son militares de alta graduación. Todos ellos iniciados en la Sociedad en 1931, coincidiendo con la instauración del régimen republicano y la constitución de nuevas logias por todo el territorio colonial.

Sin embargo, constan en nuestro listado inicial otros interesados y simpatizantes de diferentes corrientes esotéricas, como ya hemos indicado y algunas referencias a reuniones y sesiones espiritistas cuyas $\operatorname{actas}^{18}$ o informes ${ }^{19}$ se encuentran en los expedientes

\footnotetext{
${ }^{18}$ En el expediente de Manuel Montoya aparece un acta de una tenida probablemente teosófica con fecha de 3 de junio de 1932, donde se reunieron en la "Sala de Visitas del Casino de Clases", este individuo, Cristóbal de Lora, José Alberola, Venerable Maestro de Atlántida n 449 y Gran Maestre de la Gran Logia de Marruecos; Miguel Framit, hermano de Luz ${ }^{\circ}$ 449, Horacio Bruzón Carló, ya señalado, mencionándose la falta de asistencia de otro conocido masón, Venerable Maestro de Luz $\mathrm{n}^{\circ}$ 449, Rogelio González Belloto. Centro Documental de la Memoria Histórica (CDMH), Sección Masonería A, Leg. 35 Exp. 11.

${ }^{19}$ Existen varios informes elaborados por Horacio Bruzón Carló sobre la actuación espiritista y ocultista de algunos masones que cuya autenticidad parece discutible, pero que, finalmente, solo resultan haber sido exagerados. En ellos se nombra la existencia de un templo espiritista y diferentes sesiones realizadas entre 1929 y 1931 donde algunos sus miembros, como médiums, son poseídos por "Juan el Esenio". En concreto se mencionan a José de Luna Yuste, el médium principal, rechazado en Atlántida $\mathrm{n}^{\circ} 449$ por estos informes en 1931, pero miembro posterior de Alfa n 80 en 1932, Horacio Bruzón Carló, Manuel Montoya, ya señalados; Aurelio Monleón Benito también hermano de Alfa $\mathrm{n}^{\circ}$ 80; Juan Alcántara Ruiz, perteneciente a Atlántida $\mathrm{n}^{\circ}$ 448 y después a Oriente $n^{\circ} 451$; José Muñoz Espinosa miembro fundador de Luz no 449 y a posteriori de Alfa $n^{\circ} 80$; Moses Azancot de Casablanca no 346 de Casablanca; Fernando Hidalgo Moraleda de Atlántida $n^{\circ} 448$ y posteriormente de Oriente $\mathrm{n}^{\circ} 451$; $\mathrm{y}$ "De la Casa", aún sin identificar. En estos informes se critica la actuación de José de Luna y se menciona la vinculación de militares, casi todos los nombrados, en estos ritos y reuniones. CDMH, Sección Masonería A, Leg. 15 Exp. 10. En el acta de reunión mencionada en la nota anterior se discutía sobre este mismo informe, su veracidad y los motivos para culpabilizar o no la actuación de dichos hermanos que queda, no obstante, inconclusa.
} 
consultados. El número, en este caso, ascendería a la veintena, sin contar con que la generalidad de los masones que admiraban o respectaban estas doctrinas sin estar adheridos formalmente a ellas. Lejos de ser una realidad particular, la afiliación a la Sociedad Teosófica fue débil comparada con la masonería, siendo la indicada adhesión "informal" bastante mayor. Por ejemplo, existe un hermano perteneciente a El Derecho Humano, otro a la comasonería, otro al Esperantismo, pero que a penas resulta notable cuantitativamente, o al menos es poco representativo, pues se trata de un único individuo o a lo sumo dos.

En cambio, el valor cualitativo es de mayor importancia. En este sentido, fueron varios los trabajos o trazados de arquitectura que se leyeron en las tenidas al respecto de temas teosóficos, por ejemplo, sobre la figura de Jesús de Nazaret, presentado por el Juan Ibáñez Lugea, tanto para su logia Atlántida $n^{\circ} 448$ como para su grupo teosófico ${ }^{20}$ de la Rama de Bilbao, o de obras cuya autoría correspondía a personalidades principales en este campo como Annie Besant, presidenta de la Sociedad hasta 1933.

Imitando al mártir del Gólgota, el masón está dispuesto a perdonar en todas las ocasiones; las gloriosas palabras de Jesús de Nazaret, que clavado en la cruz decía "perdónalos padre mío, que no saben lo que hacen" tienen siempre eco en el corazón de todos los masones, propicios a perdonar en todo momento. Y aceptamos, propagamos y practicamos las virtudes del excelso iluminado que si no fue masón, merecía serlo ${ }^{21}$.

Tan arraigado y aceptado estaba el pensamiento esotérico en estos talleres que, incluso, se llegaron a promocionar de forma más activa sus preceptos, como por ejemplo, el deseo de difundir el esperanto como lenguaje universal ${ }^{22}$ para eliminar las diferencias socioculturales debidas a la lengua "toda vez que nada une a los hombres entre sí como el entenderse". La lengua era un problema real y constante en estas logias, sobre todo por el árabe, que desconocían la mayoría de los españoles, además de no estar del todo dominado por la mayoría de los musulmanes masones que las integraban ${ }^{23}$. También, como destacan otros trazados de Luis Antonio Montero y González, oficial de Telégrafos y miembro de Luz $\mathrm{n}^{\mathrm{o}} 449$, Sobre los orígenes de la masonería y esoterismo, donde invita al cuadro a estudiar sobre sus criterios ${ }^{24}$. O bien otra aportación que dedica este mismo hermano a la

\footnotetext{
${ }^{20}$ El trabajo consta en sus dos expedientes, el masónico y el teosófico. Fue leído en febrero de 1933. CDMH Sección Masonería A, Leg. 54 Exp. 5 y Sección Teosofía C. 5-6 Exp. 151.

${ }^{21}$ Trabajo presentado por Ramiro Farpón Pumariega para el T. Cabo Quilates, sobre las fiestas de solsticio de invierno en diciembre de 1932. CDMH Sección Masonería, Leg. 115, Exp. 11.

${ }^{22}$ Proposición realizada por la logia Cabo Espartel n ${ }^{\circ} 447$ de Alcazarquivir para la Gran Asamblea de la Gran Logia de Marruecos, sin fecha, probablemente, 1933. CDMH, Sección Masonería A, Leg. 499.

${ }^{23}$ Véanse los trabajos mencionados de Paz Sánchez, "España, Cuba y Marruecos: masonería, identidades y construcción nacional", Anuario de Estudio Atlánticos 55 (2009): 273-310. Aguiar Bobet, "La cultura de la tolerancia".

${ }^{24}$ Trabajo presentado el 22 de noviembre de 1931 a la logia $L u z n^{\circ} 449$. CDMH, Sección Masonería A, Leg. 122 Exp. 15.
} 
aludida Annie Besant ${ }^{25}$, así como una disertación sobre La Verdad, de carácter trascendental $^{26}$.

La masonería y la teosofía coincidían en algunas de sus doctrinas y ceremoniales y eran, por consiguiente, familiares la una a la otra: sus aspectos iniciáticos, la importancia del silencio y el secreto- que en principio debían guardar respecto a las enseñanzas reservadas estrictamente a sus miembros o a las reuniones realizadas - , el compromiso de adoptar una regla de vida, el compromiso también social con la Orden o Sociedad y, además, que estos preceptos sean cumplidos incluso, una vez se haya abandonado la logia sea esta masónica o teosófica.

No obstante, debemos especificar que el interés por la teosofía y el esoterismo en general en las logias masónicas se debía más bien a su aspecto intelectual y teórico, es decir, a los preceptos generales que defendía, la mayoría comunes a la masonería, como sus actividades altruistas, de beneficencia o educativas, de regeneración del espíritu, etcétera. En este aspecto, las similitudes entre teosofía y masonería eran amplias: ambas consideraban la educación como el medio para combatir los problemas sociales y a su vez, como la herramienta básica para divulgar y fomentar sus ideales, sobre todo respecto al perfeccionamiento del individuo por medio del estudio de sus doctrinas, así como de la misión que ambas se impusieron en Marruecos, la vinculación de las dos Instituciones con la Liga de los Derechos del Hombre o su posición contraria a la Pena de Muerte. A su vez, realizaban actividades similares como conferencias, celebración de centenarios, muchos de los cuales se hacían en los locales de ambas sin diferenciación o en espacios de sociabilidad común como cafés, casinos y ateneos.

También la teosofía se relacionaba con los ideales republicanos que fomentaron ambas asociaciones, eran generalmente anticlericales, antimilitaristas y pacifistas con la salvedad de que en la cuestión educativa, la masonería apoyaba un modelo laico de enseñanza, mientras que la Sociedad abogaba más por uno en el que el arquetipo de dios o la teocracia, entendida en su abstracción más general, estuviera presente, precisamente por sus postulados de tradición orientalista y el sincretismo cultural y religioso que la caracteriza. Un ejemplo de ello fue el proyecto educativo realizado a nivel internacional, con representación en España, de las iniciativas pedagógicas conocidas como La Cadena de Oro y La Tabla Redonda, donde se proponía “enseñar a los niños a que aprendan a conocer y a cumplir sus deberes para con Dios y con la humanidad ${ }^{27, "}$.

La masonería española de este periodo, en cambio, si bien no comparte el arquetipo de dios ni tampoco el ideario religioso común, tampoco lo contradice ni es atea.

\footnotetext{
${ }^{25}$ Trabajo leído el 30 de noviembre de 1931 a la logia $L u z n^{\circ}$ 449. CDMH, Sección Masonería A, Leg. 122 Exp. 15.

${ }^{26}$ Trabajo presentado el 23 de abril de 1932 a la logia $L u z n^{\circ}$ 449. CDMH, Sección Masonería A, Leg. 122 Exp. 15.

${ }^{27}$ CDMH, Sección Teosofía, Carpeta 69 Exp. 1.
} 
Opuestamente, aboga por la secularización y laicización de la enseñanza, sobre todo en el contexto norteafricano, ya que, durante la primera treintena del siglo XX en el Protectorado, la labor educativa estará principalmente en manos de congregaciones religiosas, a pesar de las reformas y los diferentes proyectos educativos realizados desde la administración española ${ }^{28}$. Varios fueron los programas planteados al respecto, aunque ninguno, salvo la concesión de becas a estudiantes con escasos recursos y de diferentes grupos (musulmanes, judíos y españoles) ${ }^{29}$, se llevaron a cabo. Por ejemplo, en la tenida del 30 de julio de 1932, uno de los diputados de la Gran Logia Regional de Marruecos ${ }^{30}$ proponía "la creación de escuelas laicas para niños y niñas de todas las razas que conviven en Marruecos (...), siempre "sin salirse en absoluto del más puro Laicismo".

Por otra parte, debemos señalar que aquellas sesiones más ocultistas u "oscurantistas" fueron rechazadas ipso facto por las logias magrebíes, del mismo modo que el fanatismo religioso de cualquier índole, la santería, el catolicismo tradicional y ultraconservador o el ateísmo. El informe antes mencionado así lo refleja, calificándose de secta al grupo guiado por José de Luna Yuste, a quien consideraban sus seguidores un médium y que, durante las décadas de 1920 y 1930 se reunían y practicaban ciertas sesiones espiritistas donde se les aparecía "Juan el Esenio":

...Pues entonces, ya que veo que usted razona lógicamente, le voy a poner en guardia contra unos señores a los cuales Ud. trata, por si le propusieran el pertenecer a su secta involucrada por la vanidad de su director ${ }^{31}$.

Este consejo, cuyo autor es el propio responsable del informe, Horacio Bruzón Carló, fue dado a un "periodista y espiritista convencido" sin identificar, para advertirle de las connotaciones falsas e improcedentes de José de Luna y sus apóstoles, sobre todo, del primero, el médium principal del grupo y su venerable. Horacio Bruzón y su hijo también formaron parte de este grupo, hecho que se presenta como prueba irrefutable de la falta de rigor y seriedad de estos individuos, la mayoría de los cuales eran masones o deseaban ingresar en la Orden y, además, eran oficiales militares de reputación estimable. De todos modos, este no es un hecho particular o exclusivo de estas logias, al contrario, la Sociedad Teosófica salvo en sus primeros pasos, condenó las prácticas espiritistas y la mediumnidad, entre otras cosas, por sus contradicciones y su atracción hacia "espíritus débiles"32. El

\footnotetext{
${ }^{28}$ Véase Irene González González, "Escuela e ideología en el Protectorado español en el norte de Marruecos (1921-1956)" (Tesis de Doctorado en Historia, Universidad de Castilla la Mancha, 2010).

${ }^{29}$ Aguiar Bobet, "La cultura de la tolerancia".

${ }^{30}$ Juan Rivaud diputado para la GLM de Lixus $n^{\circ} 446 B$ de Larache, a 30 de julio de 1932. SE Masonería A Leg. 499.

${ }^{31}$ CDMH, Sección Masonería A, Leg. 15 Exp. 10.

${ }^{32}$ Guénon, Teosofismo, 70-73.
} 
rechazo del ocultismo y los médiums en las logias masónicas y su distinción de los postulados teosóficos, por tanto, estaba justificado.

Respecto al ateísmo, por otra parte, análogo a las consideraciones de los hermanos norteafricanos sobre el obscurantismo, vemos la siguiente alocución:

...La teoría del ateísmo, pues, es aquella en la que se afirma que la muerte es el fin de todo; que el mundo carece de Dios; que el hombre no tiene alma y sí sólo materia, existiendo aquí, pero no un más allá... Este es el raciocinio de la escuela ateísta. ¿Puede satisfacer a ningún hombre de corazón, de sentimientos, de aspiraciones y de criterio? (sic) Desde luego que no, pues la evidencia de Dios ha sido esculpida en la Naturaleza (...) Negar al Supremo Hacedor es tanto como negarnos a nosotros mismos. (sic) La creencia religiosa es innata en el hombre... ${ }^{33}$.

Otros informes realizados a raíz de diferentes solicitudes de ingreso a la Orden nos confirman este rechazo generalizado hacia ambos extremos religiosos o espirituales: el primero, sobre Santiago Lozano Gómez, interventor civil, que "sin ser ateo no admite los dogmas y es enemigo de toda teocracia" "34. O bien, al respecto de Manuel Montoya Hurtado de Mendoza, señalado teósofo, cuya solicitud de iniciación se debatía en la tenida de 22 de agosto de 1931 de Luz no 449 de Tetuán con los inconvenientes de haber sido denegados. Las razones, su amistad con José de Luna, el ya mencionado médium de estos valles y la solicitud de iniciación también de este último en la logia Atlántida $n^{\circ} 448$ de Tetuán. Durante la sesión, es tildado de fanático y estafador al igual que Luna, a pesar de algunos votos a favor de este "hermano" y de que "el culto que llevan no es fanático ni inmoral" 35 . Manuel Montoya, finalmente, será iniciado, pero no en dicha logia, sino en Alfa n ${ }^{\circ} 80$ de la Gran Logia Española, donde también "vería la luz masónica” José de Luna Yuste y a la que pertenecerán la mayoría de los espiritistas masones que ya hemos indicado.

A pesar de estas diferencias, que solo afectaron a unos pocos individuos, vemos que la masonería y la teosofía no son contradictorios, tampoco del todo similares, pues son, como han apuntado algunos autores ${ }^{36}$, complementarias, por lo que unos y otros adeptos participaban en los mismos círculos y esferas, compartiendo y reflexionando a la par en sus tenidas y actividades. En suma, tenían similares maneras, por no decir una misma, basada en los principios del nuevo humanismo y el orientalismo - tenían una misma forma de interpretar y comprender el mundo.

\footnotetext{
${ }^{33}$ Artículo "El Ateísmo”, Boletín Oficial del Gran Oriente Español no 400 por Lincoln 31 ${ }^{\circ}$ (junio 1932).

${ }^{34}$ Informe de Emilio Luján de 19 de diciembre de 1933 de Santiago Lozano Gómez de Atlántida $n^{\circ} 448$. CDMH, Sección Masonería A, Leg. 15 Exp. 6.

${ }^{35}$ Libro de Actas de la Cámara de Aprendiz de $L u z n^{\circ}$ 449, 22 de agosto de 1931. CDMH, Sección Masonería A, Leg. 409.

${ }^{36}$ Véase, por ejemplo, Pedro Víctor Fernández Fernández, “Teosofía y Masonería. Pensamiento y obra de Roso de Luna", Azafea II (1989): 235-255.
} 
El problema que surge de ello, sin embargo, se caracteriza por una variable añadida que hemos ido apreciando: algunos de estos masones y teósofos tenían la particularidad de ser, en su vida profana, militares de diferente graduación.

\section{Ser masón, teósofo y militar}

En el estado actual de nuestra investigación, del mismo modo que ocurrió con los miembros de la Sociedad Teosófica, no podemos ofrecer una serie cuantitativa exacta de la presencia militar en las logias del Protectorado durante el periodo del objeto de estudio. Pero podemos afirmar que, tras la proclamación de la República, esta presencia — paralela al aumento de talleres - se deja sentir con más fuerza, aunque nunca fuese una mayoría abrumadora. En varios estudios de Manuel de Paz al respecto, se incluye esta valoración ${ }^{37}$.

Sin embargo, casi la totalidad de los integrantes de la Sociedad Teosófica y de las distintas corrientes esotéricas que se popularizaron y extendieron por el norte de África fueron nutridas por militares, como bien indican la tipología de las profesiones de los integrantes de las diferentes ramas de la Sociedad de este territorio o los propios expedientes personales de aquellos masones interesados en el espiritismo, la comasonería o los estudios esotéricos en general. En Tetuán de seis teósofos registrados, tres eran militares, y de los cuatro restantes, constaban una mujer - compañera de Cristóbal de Lora, capitán de Infantería en la década de los 20- y el resto profesaba cargos civiles. En Melilla, de treinta y seis componentes solo aparecen registrados cinco, aunque la mayoría de los expedientes están incompletos y de muchos integrantes no se conoce la profesión, lo mismo sucede en Ceuta, aunque en esta ocasión, de diez, resultan seis militares ${ }^{38}$. Los grados oscilan desde capitán, teniente, hasta oficiales de distinto rango, aunque a veces se indica únicamente el adjetivo "militar".

De todos modos, esta misma situación se encuentra en los talleres masónicos, algunos como el Triángulo Lombroso de Chauen, se componen casi en su totalidad por militares (siete de ocho en 1934), al igual que Atlántida $n^{\circ} 448$ de Tetuán cuyo registro de bajas entre 1932 y 1934 presenta veinticuatro militares frente a cincuenta y tres de profesiones varias. En cambio, Oriente no 451 tendrá en 1932 como en 1934 ocho militares en relación a un total de treinta y uno y cincuenta miembros, respectivamente. En Alfa $n^{\circ}$ 80 , la logia cuyos componentes son más aficionados al espiritismo o bien simpatizan con

\footnotetext{
37 Véanse por ejemplo de Paz Sánchez, "Masonería y militarismo en el norte de África" y "Masones y militares españoles en el Norte de África (1923-1936): un proyecto de investigación”, en La masonería y la pérdida de las colonias. Estudios (Santa Cruz de Tenerife: Ediciones Idea, 2006).

${ }^{38}$ Los datos son tomados de la tesis de Peñalba Mora, "El orientalismo en la cultura española" y están puestos en relación con el listado propio de esta investigación.
} 
sus diferentes círculos, la situación es la siguiente: nueve militares de veintisiete, según su cuadro lógico de $1934^{39}$.

No obstante, la importancia cualitativa del ejército o, más bien, de diferentes soldados y oficiales en estas logias, es mucho mayor que sus datos cuantitativos. Los cargos que ocupan en las logias o su activa participación es una muestra de ello. Muchos son venerables maestros como Cristóbal de Lora (Oriente $n^{\circ} 451$ ), Manuel Montoya (de Alfa $n^{\circ} 80$ ); también secretarios como Antonio Marañés Portales de Atlántida $n^{\circ} 448$ o Juan Ibáñez Lugea de Tetuán $n^{\circ} 64^{40}$.

Esta importancia se observa también en las persecuciones sufridas, desde los tiempos de la Dictadura primorriverista, por parte de las autoridades gubernativas. Los más afectados son los militares masones y en este caso, además, militares masones simpatizantes de diferentes movimientos esotéricos. La razón de ello, quizás por su involucración en temas políticos, explica estas constantes persecuciones, traslados e incluso encarcelamientos, como ocurrió con Cristóbal de Lora en 1931, sin ningún motivo aparente, salvo el pertenecer a la masonería. Así lo ratifican también las diversas destituciones ocurridas con la llegada del Alto Comisario de España en Marruecos este mismo año, Luciano López Ferrer, como se percibe por las quejas de estos talleres norteafricanos elevadas al Gran Consejo Federal Simbólico del Gran Oriente Español, quien había elaborado un plan orgánico para acabar con la Orden en el territorio y que afectaba tanto a los altos cargos militares como a otros profesionales civiles ${ }^{41}$; o bien en septiembre de 1933, la Gran Logia de Marruecos solicitaba el apoyo de la obediencia para que se pusiera fin a la persecución que, en el Grupo de Regulares Indígenas de Tetuán, se llevaba a cabo contra los oficiales sospechosos de "masonismo",42.

Asimismo, en 1934, a raíz de los sucesos y revueltas transcurridas en octubre en Asturias y la consiguiente confrontación de compañeros de armas por razones ideológicas, como sucedía en el Protectorado entre perseguidores (militares africanistas y antimasones) y perseguidos (masones, republicanos de izquierda, etcétera), los descontentos en las logias por la situación de España y del Protectorado iban en aumento. La conformación de un Frente Único de Izquierdas iniciado por Alfa $n^{\circ} 80$ y aceptado en la Asamblea celebrada el 17 de febrero de $1934^{43}$, no hizo más que agraviar la situación y demostrar, una vez más, su cariz inconformista respecto a la política del Estado.

\footnotetext{
${ }^{39}$ Lista de miembros de Alfa $n^{\circ} 80$ de 27 de abril de 1934. CDMH, Sección Masonería A, Leg. 605 Exp. 3.

${ }^{40}$ Solo hemos mencionado a los miembros formalizados de la Sociedad Teosófica.

${ }^{41}$ Carta al GCFS del GOE de 30 de julio 1932, discutido también en la tenida de ese día. Hasta 1934 continuarán las diversas quejas sobre estas persecuciones. Libro de Actas de la Gran Logia de Marruecos. CDMH. Sección Masonería A, Exp. 499.

${ }^{42}$ Paz Sánchez, La masonería y la pérdida de las colonias, 284.

${ }^{43}$ Propuesta firmada por los diputados de la GLM en el Acta de la Asamblea Regional de Marruecos de 17 de febrero de 1934 con el objeto de elevarla al GCFS del GOE, aunque nunca llegó a remitirse. CDMH, SE Masonería A Leg. 499.
} 
De este modo, la aparición del Decreto de 19 de julio de ese mismo año, sobre la prohibición de la participación del personal militar en cualquier actividad política, plantearía una cuestión clave para estos militares masones y teósofos: la decisión de seguir o no en estas instituciones por temor a las represalias en su "vida profana". Si bien la masonería o la teosofía no son partidos políticos per se, la discusión, sobre todo en las logias norteafricanas de tan marcado carácter político o politizadas a título individual, fue intensa, elevándose incluso las dudas sobre la afectación o no del decreto, a la condición de masón de muchos militares. Así se demuestra en el Boletín Secreto de la Gran Logia Española de septiembre de $1934^{44}$. De hecho, a raíz de esto, muchos militares solicitan la plancha quite a sus talleres respectivos, disculpándose ante sus hermanos por la decisión tomada y añadiendo siempre su carácter temporal y por prudencia, en ningún caso definitivo. Si a ello añadimos la propia desestabilización de la masonería marroquí por las persecuciones mencionadas y los propios problemas internos de las logias, se comprueba el impacto que la retirada de estos militares pudo haber tenido en la Orden.

No podemos obviar, en fin, que el papel del militarismo y su repercusión en el Protectorado fue mucho mayor que en el resto del territorio peninsular, hasta el punto de que muchos autores han planteado que la dicotomía entre civiles y militares pudo ser más relevante que las supuestas diferencias "étnicas" que existieron entre protectores y protegidos, entre cristianos, musulmanes y judíos o las de índole socioeconómica ${ }^{45}$.

Ahora bien, hablar de militares masones y además teósofos requiere, necesariamente, mencionar algunas apreciaciones al respecto de las semejanzas y diferencias que se interrelacionan en ellos. Con esto nos referimos a ciertos ideales y preceptos defendidos por la masonería y la teosofía que, en cierto modo, podrían entrar en contradicción con los cánones rigurosamente inherentes en la filosofía o cultura militar, es decir, a los binomios militarismo y antimilitarismo, el concepto de patria o nación frente a la fraternidad universal y la igualdad entre pueblos, el belicismo y antibelicismo y el siempre presente clericalismo y anticlericalismo.

La masonería y la teosofía, como ya se ha mencionado, compartían un ideario común desde sus lemas principales, la fraternidad, la tolerancia, la igualdad entre religiones, pueblos, hasta su ideología y práctica marcadamente pacifista y antimilitarista, y su crítica constante al clericalismo. Ambos, hijos del nuevo humanismo que comentábamos al inicio de este trabajo, ofrecían, en su oposición a la moral católica tradicional y familiar, al positivismo y el materialismo reinantes, una alternativa en la forma de interpretar y

\footnotetext{
${ }^{44} \mathrm{CDMH}$, Sección Masonería A, Leg. M-167.

${ }^{45}$ Véase Josep Lluis Mateo Dieste, "Una hermandad en tensión. Ideología colonial, barreras e intersecciones hispano-marroquíes en el Protectorado", $A W R A Q$ 5-6 (2012): 86. En su articulo comenta, al respecto de la división de un cementerio entre militares y civiles que este hecho "es el reflejo de una separación que ciertamente existió, como otros testimonios me comentaron; ello permite hablar de cierta complicidad entre civiles, marroquíes y españoles, ante esa hegemonía militar y el poder del uniforme, que por otro lado también sedujo a muchos marroquíes".
} 
entender el mundo. Una alternativa más espiritual, pero sobre todo, más fraternal, forjada desde y a partir del orientalismo. Esta nueva concepción del mundo, estos nuevos movimientos no podían ni pueden separarse, pues, de su origen colonialista e imperialista y, por consiguiente, orientalista. Y es en esta condición o visión orientalista de la actividad militar donde se ubican los militares africanistas (podría decirse, la versión española del orientalismo, con su propia legitimidad histórica e historicista $)^{46}$.

El principal inconveniente o la principal incongruencia de la relación entre el Ejército y las corrientes humanistas aquí tratadas, era, por su propia condición, el militarismo y con él, por defecto, el belicismo, principios ambos que definían la profesión de las armas. No ajenos a esta ambivalencia, aquellos militares masones y teósofos de estas logias del Protectorado no perdieron ocasión de valorar y discernir sobre el tema en algunos de los trabajos que leían en las tenidas semanales. Por ejemplo, Tomás Manrique Puras, teniente de Infantería, redactó un interesante discurso titulado Visión de una próxima guerra por un militar masón en el que planteó que, como miembro activo de una asociación que "persigue y labora por el bien de la humanidad" condenaba la guerra, pero que, como militar, "creyendo la guerra inevitable", cumpliría también con su juramento, especialmente si sus hermanos de nacionalidad, los españoles, se lo pedían "porque lo necesitan". De hecho, en una aportación posterior especificaba "la existencia de los ejércitos permanentes como medio de evitar las violaciones internacionales" $"$. Se trata de una visión "pacifista" de lo militar, que además concretaba de este modo en otro texto:

Yo, aunque soldado profesional en mi vida profana, soy soldado de la paz como masón, y quiero contribuir con mi insignificante esfuerzo en esa magna obra de la que es vanguardia la masonería y que tiene por objeto su consecución ${ }^{48}$.

Este objeto, nada más y nada menos, era el mismo que presentaba la masonería y la teosofía en su implantación en el Magreb, que muy poco se diferenciaba de la retórica colonial africanista de España y su ejército en la ocupación de este territorio, tal y como hemos analizado en otros trabajos y señalamos al principio de este artículo. Y además, en su extensión, esta misión y esta labor se infundía a la humanidad en general, a la magna obra de la masonería y la teosofía, la regeneración de España, la paz universal, el perfeccionamiento de la humanidad:

\footnotetext{
${ }^{46}$ Mateo Dieste, “Una hermandad en tensión”. Véase también, José González Alcantud ed. El orientalismo desde el Sur (Barcelona: Paidós, 2006).

47 Expediente personal de Tomás Enrique Puras. Trabajo presentado a Oriente $n^{\circ} 451$, CDMH, Sección Masonería A, Leg. 16 Exp. 3.

${ }^{48}$ Expediente personal de Tomás Enrique Puras. Trabajo presentado a Oriente $n^{\circ} 451$ el 1 de abril de 1933 , CDMH, Sección Masonería A, Leg. 16 Exp. 3.
} 
Yo estoy íntimamente convencido de que defendiendo a la masonería, defiendo a la humanidad y por lo tanto a mi nación, y de que defendiendo a mi nación defiendo a la humanidad (...). El militar puede, si quiere, ser bueno; no es, como dicen, malo por naturaleza. Estudiad las guerras y allí encontraréis numerosos rasgos de filantropía; veréis como un soldado abandona a su inseparable compañero, a su fusil, para socorrer al enemigo herido; veréis cómo el jinete abandona su caballo con grave riesgo para él, para cederlo a quien no puede caminar ${ }^{49}$.

Pero las similitudes de este trinomio van más allá, sobre todo si tenemos en cuenta los aspectos básicos del autoritarismo y el estamento militar: el orden como bien supremo y la unidad y la jerarquía como sustentadoras suyos. Las dos asociaciones antimilitaristas, así como la propia estructura de otras corrientes espiritistas, son jerárquicas, ritualistas, con un ceremonial que exige disciplina, trabajo, sacrificio, compañerismo $\mathrm{y}$, ante todo, cumplimiento del deber. Por lo tanto, sus aspectos formales y estructurales son, en esencia, muy similares a la estructura militar. Prácticamente en cada trabajo, discurso o acta de los talleres masónicos, así como en las disertaciones teosóficas, observamos que estos condicionantes se repiten constantemente. Juan Ibáñez Lugea, miembro activo de los tres grupos, ilustra estas deferencias:

Grabad en vuestras mentes las palabras trabajo y deber; entusiasmo e íntima satisfacción; poned sobre todas Amor. Esas cinco palabras, claves, encierran un programa formidable de vida. (...) Conservad el recuerdo del cuartel, de este internado en el que, sobre la misma vida aprendéis la página más interesante; la de la solidaridad y el compañerismo; al de la unión y convivencia sin distinciones; la de la amistad y el amor sin prejuicios. No olvidéis el concepto disciplina, disciplina consciente. Es necesaria en los pueblos, en las sociedades, en las familias, e el individuo, disciplina es orden y método; sed disciplinados sintiendo el hermoso concepto. Por otra parte sabed que no podréis escapar a él; rige en todo y para todo; en uno u otro sentido, en una u otra escala, desde los universos hasta los más insignificantes seres, se mueven supeditados a la disciplina que es el contenido de la Ley de la Armonía.

A todos: que elevéis el concepto deber a la categoría de supremo ideal: que os hagáis dignos del triple título-Hombre, soldado, ciudadano- que ostentáis ${ }^{50}$.

\section{Contradicciones previas a la guerra}

En el capítulo VII del libro Masonería y Ejército en la Segunda República ${ }^{51}$, Luis Lavaur preguntaba "¿qué pudo inducir en el contexto español de los años treinta a ciertos

\footnotetext{
${ }^{49}$ Expediente personal de Tomás Enrique Puras. Trabajo presentado a Oriente $n^{\circ} 451$ el 25 de marzo de 1933, CDMH, Sección Masonería A, Leg. 16 Exp. 3.

${ }^{50}$ Trabajo sobre la nación y diferentes reflexiones sobre la República de Juan Ibáñez Lugea, teniente de Infantería, sin fecha, CDMH, Sección Teosofía, Carpeta 5-6 Exp. 151.
} 
mandos del ejército a ingresar en una organización no ilegal, pero secretísima, clandestina y misteriosa, de la que se sabía poco y más mal que bien?” y “¿qué impulsos racionales o emocionales pudo empujar a militares de carrera a enrolarse, o continuar enrolados, en una asociación claramente pacifista a ultranza cuando no antimilitarista, y tan mal vista por el común de sus compañeros? Sus conclusiones son claras: "en las logias del quinquenio republicano, no se rindieron grandes homenajes al Gran Arquitecto del Universo, ni se cultivaron mucho los rituales litúrgicos y las esoterías decimonónicas ya en un desuso bastante general. Partiendo de la variedad de incentivos, cabe la posibilidad de la existencia de militares que, animados de las mejores intenciones, ingresaron en la Orden por entender que ingresaban en una organización liberal y liberadora". (...) También "ingresaron por motivos pragmáticos, por considerar a la logia una fraternidad de ayudas mutuas, atraídos por la posibilidad de medrar en su carrera".

Sin embargo, continúa este autor, la afiliación de los militares españoles,

... por encima de cualquier otra consideración fue de índole política. Se creó así en 1936 una situación de alto riesgo en la cúpula de un ejército, al escindir este en dos bandos antagónicos. Uno de ellos minoritario afiliado a una organización de signo antifascista y pacifista a ultranza, radicalmente opuesto a la filosofía de la milicia, a la escala de valores y al espíritu tradicionalmente preservado por la mayoría de la familia militar. Una contradicción de fuerzas ideológicas en el seno del estamento depositario del armamento de la nación, por equilibrada, propensa a resolverse en catástrofe $^{52}$.

En otro artículo, esta vez de Louzao Villar" ${ }^{53}$, leemos, “pero, ¿qué significó ser teosofista en la España de la primera mitad del siglo XX? (...) Lo que parece claro es que, aun con la diversidad de recorridos vitales, la llegada al teosofismo se estableció a partir de una búsqueda espiritual individual tras la ruptura o alejamiento del catolicismo familiar. Se podrían seguir diversos caminos, pero en general todas las biografías que hemos podido completar hasta la fecha coinciden en este punto. Al mismo tiempo, nos ofrecen una información de primera mano sobre uno de los aspectos más desconocidos por la historiografía española, como es la evolución de aquellas personas que se alejaron del catolicismo, la temida "apostasía de las masas" a la que se refirió el religioso católico Maximiliano Arboleya, "pero no recalaron en el ateísmo o la increencia, sino que comenzaron una búsqueda espiritual particular".

51 Luis Lavaur, Masonería y Ejército en la Segunda República, (1931-1939) (Madrid: Cultura y Publicaciones, 1997), 81-87.

${ }_{52}^{52}$ Lavaur, Masonería y Ejército, 87.

53 Joseba Louzao Villar, "Los idealistas de la fraternidad universal. Una aproximación a la historia del movimiento teosófico español (1890-1939)", Historia Contemporánea 37 (2008): 527-528. 
La relación de ambas perspectivas quizás no sea tan obvia, pero a lo largo de estas páginas hemos intentado conciliar tres mundos aparentemente diversos y enfrentados donde tal vez, las individualidades estén por encima de la generalidad, pero que no dejan de tomar forma y volumen en el contexto que nos ocupa. El hecho es que, si bien existieron numerosos militares republicanos miembros activos de la masonería y, a su vez, simpatizantes de diversas corrientes teosóficas y esotéricas, la razón se debe a la complementariedad entre sus ideales, formas y objetivos tanto en lo que respecta a Marruecos y su condición colonial y al destino de la nación española o de la propia humanidad, como a una búsqueda más individual, regeneracionista de la vida civil española, del contexto político y social que concentraba fuertes contrastes ideológicos y políticos, tanto a nivel nacional como internacional.

No olvidemos que estos masones, militares y teósofos, confluían en diversos espacios, asociaciones políticas y culturales y que, a su vez, estaban interesados en todos los sucesos de la época, para los cuales tenían una especial sensibilización, tal y como reflejan en sus cartas, actas, trabajos, etcétera. Sin olvidar otras razones personales que pudieron ser de índole política, profesional o espiritual, la realidad es que el ideal y la misión que se imponía el Ejército para proteger a España, precisamente por lo que había significado y significó esta Institución durante los siglos XIX y XX, no chocaba, en su esencia, con los ideales masónicos y teosóficos para el mismo fin. Era una simbiosis natural, en la que la protección militar iba pareja a la seguridad civil y a la protección más ética y subjetiva del individuo. Todo formaba parte de ello, pero desde distintas esferas. Era una labor y una misión concreta de alto contenido moral y social.

Las contradicciones acaecidas se producirían más bien por otros factores, como el que indicamos al respecto del Decreto del 19 de julio de 1934, en el que se produce una ruptura real entre lo militar y estas asociaciones, produciéndose lo inevitable: por contexto y a tenor de las circunstancias primaba el ser militar a ser masón, teósofo o espiritista. Esto mismo sucedería en 1936 una vez que estalla la guerra civil.

En definitiva, la visión que tenemos del Ejército y de determinadas organizaciones heterodoxas se nos presenta, de hecho, mucho más compleja de lo que pudiera parecer a primera vista. Un sector de miembros de la milicia creyó, probablemente, que integrándose en organizaciones teosóficas y masónicas podría contribuir a cambiar determinados aspectos sociales que, en el caso del Protectorado de Marruecos, adquieren una dimensión más densa y compleja, debido al carácter colonial. Estos militares habían heredado las tradiciones liberales del siglo XIX, su implicación en la regeneración nacional y tuvieron la originalidad y la valentía de buscar un camino diferente (y minoritario) entre los caminos posibles de un futuro pletórico, en lo nacional y en lo internacional, de grandes incertidumbres. Ser masón o teósofo para un militar y un ciudadano del siglo XX constituía no solamente un atractivo individual, sino la implicación en un proyecto transformador esencialmente moderado, al margen de exageraciones propagandísticas. Todo ello obliga, 
como es lógico, a seguir profundizando en el análisis individualizado de todos estos personajes.

\section{Bibliografía}

Aguiar Bobet, Valeria. "La cultura de la tolerancia en el Marruecos de la II República: el VIII Centenario de Maimónides”. Editado por José Miguel Delgado Idarreta e Yván Pozuelo Andrés. En La masonería hispano-lusa y americana. De los absolutismos a las democracias (1815-2015) (Zaragoza: CEHME, de próxima publicación (2017).

Albellán García-González Árbol, José Luis. El problema de España y la cuestión militar. Madrid: Editorial Dykinson, 2005.

Alvarado, Javier, Masones en la nobleza de España, Una hermandad de iluminados. Madrid: La Esfera de los Libros, 2016.

Blavatsky, Helena P. La Clave de la Teosofía. Traducción de Consuelo Burón Guillén. Barcelona: Editorial Teosófica, 1889.

Chaves Pacheco, José Ricardo. "El estudio académico de lo esotérico". REHMLAC 7, no. 2 (mayo-noviembre 2015 [citado el 5 de agosto de 2016]): disponible en http://revistas.ucr.ac.cr/index.php/rehmlac/article/view/19948

Faivre Antoine, Needleman Jacob, comps. Espiritualidad de los movimientos esotéricos modernos. Barcelona: Paidós, 2000.

Fernández Fernández, Pedro Víctor. "Teosofía y Masonería. Pensamiento y obra de Roso de Luna". Azafea II (1989): 235-255.

Fernández Malanda. "Dolores, Maçons, espiritistes i lluirespensadors en el debat educativ del segle XIX”. Temps d'Educació 30 (2006): 303-316.

González Alcantud, José Antonio, ed. El Orientalismo desde el sur. Barcelona: Consejería de Cultura, Junta de Andalucía, Anthropos Editorial, 2006.

González González, Irene. Escuela e ideología en el Protectorado español en el norte de Marruecos (1921-1956). Tesis de Doctorado en Historia, Universidad de Castilla la Mancha, 2010.

Guénon, René. Teosofismo, historia de una pseudo-religión. Traducido por C. J. Vega. Montevideo: Edición digital de la Dirección de Educación del Ministerio de Educación y Cultura, s.a. [citado el 16 de febrero de 2016]): disponible en http://www.edu.mec.gub.uy/biblioteca_digital/libros/G/Guenon, \%20Rene\%20\%20religion.pdf

Hanegraaff, Wouter J. Esotericism and the Academy. Rejected Knowlegde in Western Culture. Cambrigde: Cambrigde University Press, 2012.

Hanegraaff, Wouter J. "The Globalization of Esotericism”. Correspondences 3 (2015): 5591. 
Lavaur, Luis. Masonería y ejército en la Segunda República (1931-1939). Madrid: Cultura y Publicaciones, 1997.

Lleixà Chavarría, Joaquim. Contrarrevolución monárquica y militarismo en la España de los años 30. Tesis de Doctorado en Historia, Universidad de Barcelona, 1985 [citado el 16 de febrero de 2016]: disponible en http://www.tdx.cat/handle/10803/1396;jsessionid=E2E200C46D6F5EE555E6E3D74E 52DF64.tdx 1

Louzao Villar, Joseba. "Los idealistas de la fraternidad universal. Una aproximación a la historia del movimiento teosófico español (1890-1939)". Historia Contemporánea 37 (2008): 501-529.

Mateo Dieste, Josep Lluis. "Una hermandad en tensión. Ideología colonial, barreras e intersecciones hispano-marroquíes en el Protectorado". AWRAQ 5-6 (2012): 79-96.

Paz Sánchez, Manuel de. "Antibelicismo y pacifismo en la masonería española". Hispania XLVIII, no. 169 (1988): 737-754.

Paz Sánchez, Manuel de. Militares masones de España. Diccionario biográfico del siglo $X X$. Valencia: Centro Francisco Tomás y Valiente UNED- Fundación Instituto de Historia Social, 2004.

Paz Sánchez, Manuel de. La masonería y la pérdida de las colonias. Santa Cruz de Tenerife: Ediciones Idea, 2006.

Paz Sánchez, Manuel de. "España, Cuba y Marruecos: masonería, identidades y construcción nacional”. Anuario de Estudio Atlánticos 55 (2009): 273-310.

Penalva Mora, Vicente. El orientalismo en la cultura española en el primer tercio del siglo XX. La Sociedad Teosófica Española (1888-1940). Tesis de Doctorado en Historia, Universidad Autónoma de Barcelona, 2013.

Pomés Vives, Jordi. "Diálogo Oriente-Occidente en la España de finales del siglo XIX. El primer teosofismo español (1888-1906): un movimiento religioso heterodoxo bien integrado en los movimientos sociales de su época". Revista HMIC IV (2006): 55-75.

Roldán Rodríguez, Luis. Militares de la República: Su segunda guerra civil. Madrid: Ediciones Vosa, 2000.

Serrano Seco, Carlos. Militarismo y civilismo en la España Contemporánea. Madrid: Instituto de Estudios Económicos, 1984.

Versluis, Arthur. "What is esoteric? Methods in the Study of Western Esotericism". Esoterica IV (2002 [citado el 16 de febrero de 2016]): disponible en http://www.esoteric.msu.edu/VolumeIV/Methods.htm 